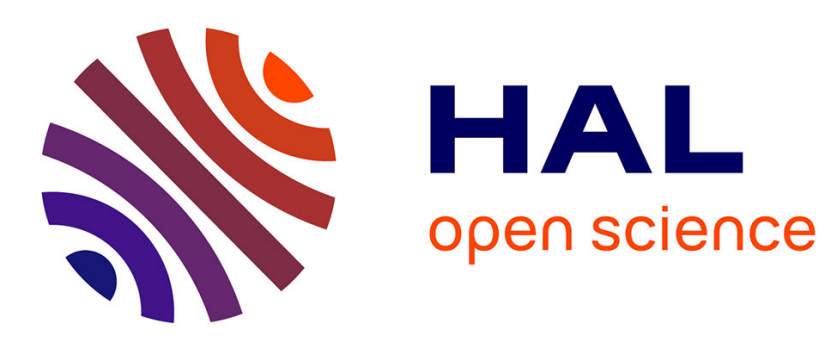

\title{
How charisma is perceived from speech. A multidimensional approach
}

Rosario Signorello, Francesca d'Errico, Isabella Poggi, Didier Demolin

\section{To cite this version:}

Rosario Signorello, Francesca d'Errico, Isabella Poggi, Didier Demolin. How charisma is perceived from speech. A multidimensional approach. 2012 ASE/IEEE International Conference on Social Computing, Sep 2012, Amsterdam, Netherlands. pp.435-440, 10.1109/SocialCom-PASSAT.2012.68 . hal-00728891

\section{HAL Id: hal-00728891 \\ https://hal.science/hal-00728891}

Submitted on 7 Sep 2012

HAL is a multi-disciplinary open access archive for the deposit and dissemination of scientific research documents, whether they are published or not. The documents may come from teaching and research institutions in France or abroad, or from public or private research centers.
L'archive ouverte pluridisciplinaire HAL, est destinée au dépôt et à la diffusion de documents scientifiques de niveau recherche, publiés ou non, émanant des établissements d'enseignement et de recherche français ou étrangers, des laboratoires publics ou privés. 


\section{How charisma is perceived from speech. A multidimensional approach}

\author{
Rosario Signorello \\ GIPSA-Lab, UMR 5216 CNRS \\ Grenoble INP/UJF/Stendhal University \\ Grenoble, France \\ Educational Dept., Roma Tre University \\ Rome, Italy \\ Email: rosario.signorello@gipsa-lab.fr
}

\author{
Francesca D'Errico, Isabella Poggi \\ Educational Dept., Roma Tre University \\ Rome, Italy \\ Email: \{derrico,poggi\}@uniroma3.it
}

\author{
Didier Demolin \\ GIPSA-Lab, UMR 5216 CNRS \\ Grenoble INP/UJF/Stendhal University \\ Grenoble, France \\ Email: didier.demolin@gipsa-lab.fr
}

\begin{abstract}
A leader's charisma is conveyed by various multiple aspects of his perceivable behavior among which the acousticprosodic characteristics of speech. We present here a study on the perception of charisma in political speech that aims to investigate the notion of charisma and to validate a theoretical framework on a multidimensional scale of charisma perception. The study points out that a multidimensional approach of charisma allows to better analyze which factors are related to specific aspects of speech. We finally clustered the charismatic voice of an Italian political leader in three factors: Proactive-Attracting, BenevolentCompetent and Authoritarian.
\end{abstract}

Index Terms-charisma, political speech, intonation contour, illocution, voice disorder.

\section{INTRODUCTION}

Charisma was firstly described by Weber as an "extraordinary quality" of a person who is believed to be endowed with superhuman properties thanks to which s/he gets acknowledged as a leader [1, p. 5]. According to Weber, the charisma causes a devoted following from the leaders followers that is expressed by attitudes ranging from "trust" to "faith" and that creates the "cult of the leader" [1, p. 17]. Furthermore, in Weber's theory, the charisma finds its place in the political sphere to promote the renewal and the progress of civilization [1, p. 8].

Though no specific objective description of the "extraordinary quality" was given in Weber's studies, some works started to study the perceivable behaviors of charismatic leaders: some (e.g., [2]) focus on what we may call the "charisma of the mind", that dwells in the strength of a leader's ideas, others (e.g., [3]) try to find visually or acoustically perceivable aspects of a leader's behaviors that we may call "charisma of the body".

In our general framework we assume that some of the perceivable acoustic-prosodic characteristics of a leader's speech are specifically responsible for conveying charisma. We aim to understand how much the acoustic and prosodic characteristics of speech influence the perception of speech acts in discourse, and how this is crucial in the process of persuasion. In particular we try to distinguish, in samples of political speech, a charismatic speech from a non charismatic one and to isolate the acoustic patterns that make the voice of a leader a charismatic voice.

Within previous work investigating the relationship between the acoustic-prosodic characteristics of a political leader's speech and the perception of his/her charisma, [4] studied the correlation between acoustic, prosodic, and lexicosyntactic characteristics of political speech and the perception of charisma; [5] investigated the prosodic features of rhetoric utterances in French political speech in pre and post-elections discourses. Other works examined the relationship between prosodic features and the perception of a speaker as a "good communicator" [6] or analyzed the intonation contour of French political leaders' speech and its idiosyncratic and contextual variations [7].

The study presented here, built on a previous work [8], extends our general theoretical framework on the phenomenon of charisma and its perception in political speech, and validates this framework by means of a perceptual evaluation study.

From the point of view of social computing, our research has possible applications in the development of tools for speech synthesis, in particular, the synthesis of "charismatic" speech. It might improve the speech synthesis used for example in Speech Generating Devices (SGDs), and further, combined with speech recognition, it could be used to improve the speech synthesis used in the interaction between humans and computers via Natural Language Processing (NLP) devices as Embodied Conversational Agents (ECA). In fact, giving the synthesized voice a "charismatic" aspect might allow the nonhuman interface to be felt as more "human" during the interaction process, and possibly to be reach higher effectiveness in terms of Persuasive Computing [9].

\section{A MULTIDIMENSIONAL HYPOTHESIS ABOUT CHARISMA}

According to [10], in persuasive discourse the speaker tries to convince the audience to do some action by exploiting the three strategies posited by [11]: Logos (the rational argument), Pathos (the appeal to the audiences emotions), and Ethos (the character of the speaker). According to [10] and [12]'s theory, the dimension of Ethos also includes, for the political leader, three sub-dimensions: Benevolence (the tendency to act in the 
interest of the audience), Competence (the capacity for rational foreseeing and planning), and Dominance (the power to prevail in a competition).

The notion of charisma we propose here is based on this theoretical framework. We define charisma as a set of characteristics of a leader that are displayed by features of her/his communicative and non-communicative behavior and result in "charisma of the body" and in the "charisma of mind". Then, we went more into these characteristics by investigating what adjectives do people use to describe the qualities of a charismatic leader. We administered a questionnaire through the Web to 58 French participants ( 42 female, 16 male, mean age 30), asking to freely generate adjectives connected to the idea of what charisma is and what it is not. We obtained a list of 106 adjectives describing charisma positively and 105 describing what charisma is not. Out of these we selected 67 adjectives (see TABLE I) retaining only those occurring more than once: 40 of them were positively and 27 negatively related with charisma. According to previous studies [10] and [12] we grouped the adjectives around the dimensions of Pathos and Ethos (through its three sub-dimensions) and of the Effects of Emotional Induction:

i) Pathos: the charismatic leader is endowed with a high degree of emotional intelligence [13] that is the ability to feel emotions (as described for instance by adjectives like enthusiastic or passionate), and to feel and display empathic with one other's emotional state (e.g., empathetic);

ii) Ethos Benevolence: (sociability, inclusiviteness): the charismatic leader is people-oriented, s/he is inclusive, s/he makes the others feel "similar" to her/him and even "together" with her/him (e.g., extraverted, sociable);

iii) Ethos-Competence: the charismatic leader owns unconventional qualities in terms of cognition (e.g., visionary, creative), volition (e.g., determined, enterprising) and communication skills (e.g., communicative, clear, persuasive);

iv) Ethos Dominance: the charismatic leader has a dominant personality in terms of activation (e.g., active, dynamic), power and persistence (e.g., courageous, vigorous) and appeal (e.g., captivating, convincing).

v) Effects of Emotional Induction: the charismatic leader has a high capacity to influence others by inducing emotions in them. For example, when listening to or being with him/her, a person may feel charmed, seduced or fascinated (e.g., enumerate, attractive, charming).

\section{WHAT MAKES A SPEECH CHARISMATIC? A PERCEPTION STUDY TO VALIDATE THE SCALE OF CHARISMA}

In a previous work [8], we analyzed the change in the voice characteristics of Umberto Bossi, an Italian politician who in 2004, during his political career, had a stroke that resulted in severe speech impairment. Bossi is one of the founders of the Lega Nord - per l'indipendenza della padania (North League for the Independence of padania), a federalist and populist
TABLE I

THE 67 POSITIVE AND NEGATIVE ADJECTIVES RELATED WITH CHARISMA COLLECTED AMONG THE NAÏVE FRENCH PARTICIPANTS (IN ENGLISH FOR CLARITY PURPOSES).

\begin{tabular}{|c|c|c|}
\hline DIMENSION & Positive ADJ. & NEGATIVE ADJ. \\
\hline Pathos & $\begin{array}{l}\text { passionate, empathetic, enthu- } \\
\text { siastic, reassuring }\end{array}$ & cold, indifferent \\
\hline $\begin{array}{l}\text { Ethos Benev- } \\
\text { olence }\end{array}$ & $\begin{array}{l}\text { extraverted, } \\
\text { spontaneous, } \\
\text { honest, fair, } \begin{array}{r}\text { trustworthy, } \\
\text { friendly, } \\
\text { easygoing, makes the others } \\
\text { feel important }\end{array} \\
\end{array}$ & $\begin{array}{l}\text { untrustworthy, } \\
\text { dishonest, egocentric, } \\
\text { individualistic, } \\
\text { introverted }\end{array}$ \\
\hline $\begin{array}{l}\text { Ethos Com- } \\
\text { petence }\end{array}$ & $\begin{array}{l}\text { visionary, organized, smart, } \\
\text { sagacious, creative, competent, } \\
\text { wise, enterprising, determined, } \\
\text { resolute, who propose, seduc- } \\
\text { tive, exuberant, sincere, clear, } \\
\text { communicative }\end{array}$ & $\begin{array}{l}\text { inefficient, } \\
\text { inadequate, uncertain, } \\
\text { faithless, unclear, } \\
\text { menacing }\end{array}$ \\
\hline $\begin{array}{l}\text { Ethos Domi- } \\
\text { nance }\end{array}$ & 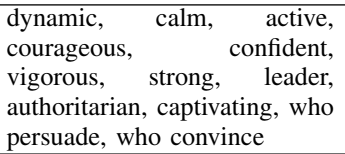 & $\begin{array}{l}\text { apathetic, timorous, } \\
\text { weak, conformist, } \\
\text { unimportant, who } \\
\text { scare }\end{array}$ \\
\hline $\begin{array}{l}\text { Emotional } \\
\text { Induction } \\
\text { Effects }\end{array}$ & $\begin{array}{l}\text { charming, attractive, pleasant, } \\
\text { sexy, bewitching, eloquent, in- } \\
\text { fluential }\end{array}$ & boring \\
\hline
\end{tabular}

Italian political party whose aim is the foundation of a new independent country called "padania" through the secession of all the northern regions from Italy. He has been recognized as the charismatic leader of this party for 21 years, since its foundation in 1991 to 2012.

Our point was that, if the acoustic-prosodic patterns of Bossi's speech, preceding and following the stroke, give rise to a different perception of charisma we might conclude that the information about charismatic qualities is borne by the prosodic characteristics that vary across the two samples.

\section{A. Method}

We collected two samples taken from two speeches performed by Bossi, respectively, in 1994 (PRE-stroke) and in 2011 (POST-stroke). By measuring their acoustic features and analyzing their intonation contour we singled out their main differences. Then we conducted a perceptual study on how the two samples were perceived as charismatic by French subjects.

Previous works about the perception of a speaker as a good [6] or charismatic speaker [4] rely on the acoustic analysis and the perceptual evaluation of stimuli classified per speaker, topic and genre of speech. Our approach was different. For each of the two conditions (PRE and POST stroke) we selected 3 stimuli differing for their respective illocutionary value: one assertion, one incitation and one rhetorical wh- question. As we know, the speaker shapes prosody [14] differently in relation to different speech acts. Our hypothesis was that all three types of speech act are perceived as more charismatic in the PRE condition thanks difference in acoustic features. Further we argued that an incitation might be perceived as more charismatic than a rhetorical question, which in turn might be perceived as more charismatic than an assertion. We 
(a)

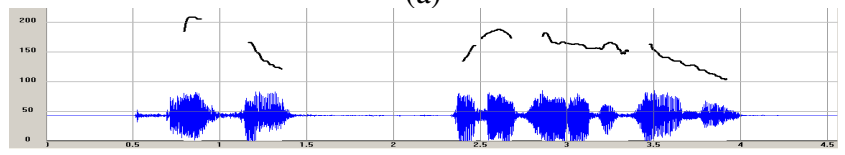

(b)

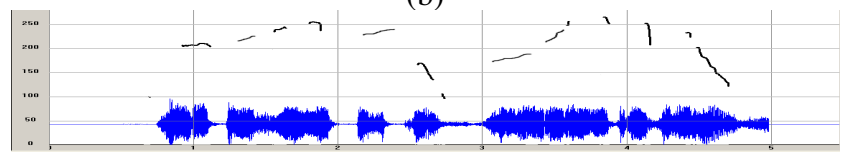

(c)

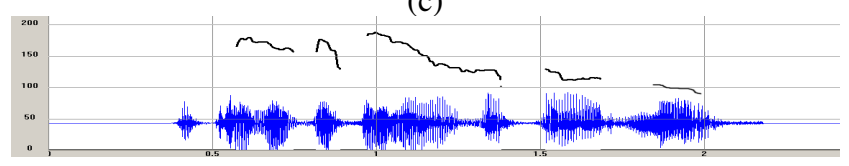

Fig. 1. Intonation contour, transcription, translation, duration and $f_{0}$ measures of PRE stimuli per speech act. (a): Assertion. "Questo amici ereditiamo" [This, my friends, is what we inherit]. 3,51s. $f_{0}$ mean $52.62 \mathrm{~Hz}$ SD $12.40 \mathrm{~Hz}$; $\min 95.25 \mathrm{~Hz}$; $\max 210.94 \mathrm{~Hz}$; range $13 \mathrm{ST}$. (b): Incitation. "Si ritorna all'attacco, fuori dalle trincee" [Let's take up again the offensive, get out of the trenches]. 4.27s. $f_{0}$ mean $225.51 \mathrm{~Hz}$; SD $38.58 \mathrm{~Hz}$; min 107.74 $\mathrm{Hz}$; $\max 270.36 \mathrm{~Hz}$; range $16 \mathrm{ST}$. (c): Rhetorical wh- question. "E come facevamo a farlo?" [How could we have done it?]. 1.81s. $f_{0}$ mean 138.28 Hz; SD $27.98 \mathrm{~Hz}$; min $96.07 \mathrm{~Hz}$; max $189.39 \mathrm{~Hz}$; range 11.72 ST. Reprinted from [8]. Spectrogram and intonation contours graphics obtained with [18].

analyzed the acoustic parameters and intonation contour of our stimuli as described below.

1) Overall $f_{0}$ measures: "[The] measures related to the rate of vocal folds vibration (the fundamental frequency, or $f_{0}$ ) are particularly important [...] because of the great importance that pitch (the perceptual correlate of $f_{0}$ ) has for many aspects of voice perception" [15, p. 54]. The PRE speech presents higher $f_{0}$ means than POST speech: PRE $\left(f_{0}\right.$ mean $178.89 \mathrm{~Hz}$; $\min 101.84 \mathrm{~Hz}$; $\max 241.10 \mathrm{~Hz}$ ), POST $\left(f_{0}\right.$ mean $120.20 \mathrm{~Hz}$; $\min 91.78 \mathrm{~Hz}$; $\max 155.99 \mathrm{~Hz}$ ). All means from the PRE differ significantly from the POST $(\mathrm{p}<0.0001)$. Our findings confirm and extend [16]'s findings on significant differences in $f_{0}$ measures between normal and disordered voice. As mentioned above higher $f_{0}$ values might be positively correlated to charisma perception.

2) Intonation contour description: When we talk, or when we read, we perceive a sort of musical rhythmic pitch with notes that change in highness, linked to every syllable, every statement and every sentence [17, p. 13-14]. This is called "intonation contour" or "pitch contour" and it represents the perceptual correlate of the fundamental frequency. Below we describe this contour highlighting the important differences between the PRE and POST speech that might be relevant in the different perception of Bossi's speeches:

- The assertion in the PRE condition (Fig. 1a) presents a syntactic focus on "questo" [this], emphasized by a falling intonation contour and separated by a pause from the rest of the sentence. The right-side part of the tonal unit presents a falling contour with a small peak on the last tonic syllable. Instead, in the POST condition (Fig. 2a) the sentence presents a moderate falling and flat intonation contour with a peak on the third lexical (a)

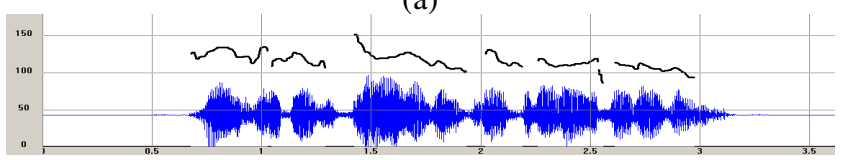

(b)

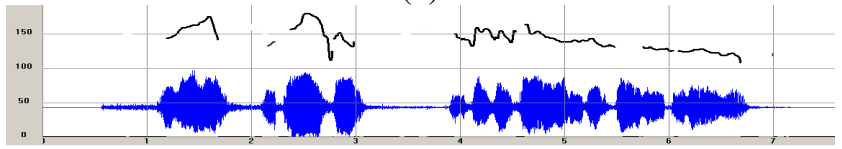

(c)

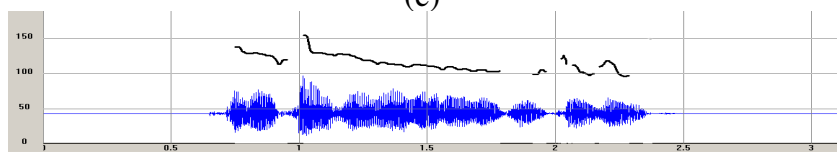

Fig. 2. Intonation contour, transcription, translation, duration and $f_{0}$ measures of POST stimuli per speech act. (a): Assertion. "Noi siamo schiavi del centralismo romano" [We are slaves of the Roman centralism]. 2,46 s, $f_{0}$ mean $116.77 \mathrm{~Hz}, \mathrm{SD} 10.74 \mathrm{~Hz}, \min 86.64 \mathrm{~Hz}, \max 146.45 \mathrm{~Hz}$, range 9 ST. (b): Incitation. "La Lega è pronto per conquistare la libertà della padania" [The Lega is ready to conquer the freedom of padania]. 6.61s, $f_{0}$ mean $142.02 \mathrm{~Hz}, \mathrm{SD} 38.58 \mathrm{~Hz}, \min 86.2 \mathrm{~Hz}$, max $182.08 \mathrm{~Hz}$, range $12 \mathrm{ST}$. (c): Rhetorical wh- question "E come fanno a lavorare questa gente?" [How can these people work?]. $1.89 \mathrm{~s}, f_{0}$ mean $117.93 \mathrm{~Hz}, \mathrm{SD} 15.54 \mathrm{~Hz}$, min $90.56 \mathrm{~Hz}, \max 192.99 \mathrm{~Hz}$, range 13 ST. Reprinted from [8]. Spectrogram and intonation contours graphics obtained with [18]

word.

- The incitation in the PRE condition (Fig. 1b) includes two parts, each with an intonation contour starting with high frequency and falling sharply in the last tonic syllable. In the POST condition instead the incitation (Fig. 2b) presents two rising-falling contours in the first part and falls gradually in the right part of the tonal unit.

- The rhetorical wh- question in the PRE condition (Fig. 1c) presents two contiguous intonation contour movements; the raising contour corresponds to the wh- element, the falling part corresponds to the verb. A gradual falling movement comes on the right side of the tonal unit. In the POST statement (Fig. 2c) a falling contour corresponds to the wh- element and a raising contour to the verbal element, with a gradual falling movement on the right side of the tonal unit.

3) Perception study: All the intonation contour's features presented above, very evident in the PRE speech are almost absent in the POST speech. The important difference in the intonation contour and in $f_{0}$ features showed above and in Fig. 1 and Fig. 2 between the PRE and the POST speech should, in our hypothesis, influence the perception of Bossi's speech. More specifically, we hypothesize that the richer the prosody (higher $f_{0}$ values as max, min and range, focus on key words, tonal jumps, rising and falling contour, etc.) the more charismatic the speaker will be perceived. To test this hypothesis, we conducted a perception study aimed at investigating how charismatic these stimuli were rated. To avoid biases induced by the comprehension of the verbal message, similar to [19], that asked judges to attribute personality traits from nonverbal vocal behavioral cues in an unknown language, 
we asked 40 French participants with no knowledge of Italian to rate our stimuli. As [19] did for personality traits, we also made the hypothesis that the acoustic-prosodic pattern conveys sufficient cues to allow participants to judge the level of charisma borne by the stimuli. 20 participants listened to the PRE condition and 20 to the POST condition stimuli. The test took place in an anechoic chamber and participants wore a Sennheiser HD 25-13 headphone. After listening to each stimulus a participant had to answer to some check questions to verify that the perception of the acoustic signal was optimal and that the semantic content was not understood. Then they had to express their judgment about the stimuli through the 67 adjectives inventory of the multidimensional scale of charisma (see TABLE I) on a 7-point Likert scale ( 0 = "totally disagree", 7 = "totally agree", with some adjectives from the list substituted by their reverses (e.g., warm instead of cold) to avoid answer habituation. The average duration of the test was of 25 minutes.

\section{B. Results}

In the section above we presented a summary of a previous study [8], in which we tested the hypothesis on the perception of charisma through the speech by considering each single adjective in the multidimensional scale of charisma. We also tested the general tendencies of charisma in relation to the independent variables manipulated: pre- and post-stroke condition and type of speech act.

The aim of the study presented here is to look at possible latent factors in the characteristics of charisma, and to test which of them are influenced by the acoustic-prosodic pattern of Bossi's speech. To do so, we tried to reduce the number of variables by finding a smaller number of factors to group our 67 adjectives. First of all, through an Exploratory Factor Analysis (EFA) we obtained twelve factors. Then, we performed a Varimax Rotation of the factors obtained by the previous analysis. We obtained a significant Bartlett's test of sphericity $(\mathrm{p}=.000)$ and an optimal Kaiser-Mayer Olkin (KMO) measure of Sampling Adequacy (.83). From the Varimax Rotation we extracted three factors which explained $45 \%$ of the variance (respectively the first $22,52 \%$, the second $12,60 \%$ and the third $10,83 \%$ ) and we obtained the factor loadings presented in TABLE II. The three factors show a high level of reliability (respectively: Factor $1 \alpha=.92$, i.i. $=0.52$; Factor 2 : $\alpha=.87$, i.i.= 0.44; Factor 3: $\alpha=.90$, i.i. $=0.41$ ). So we proceeded to compute three different variables by summing the score of the 15 items for the Factor 1, 11 items for Factor 2 and 14 items for the Factor 3 .

Thus we obtained an index of perception (Fig. 3) of a Proactive-Attracting charisma (Factor 1$)(\min =1 ; \max =6.6$; mean=3.53; DS=1.20), an index of Benevolent -Competent charisma (Factor 2) $\quad(\min =1.2 ; \quad \max =6.64 ; \quad$ mean=3.47; $\mathrm{DS}=1.09$ ) and finally one of Authoritarian-Threatening charisma (Factor 3$)(\min =1 ; \max =6.7 ;$ mean=4.32; $\mathrm{DS}=1.21)$. We ran a t-test analysis on one paired-sample and as illustrated in Fig. 3 the Factor 3 is significantly $(\mathrm{p}<0.001)$ the highest
TABLE II

ROTATED COMPONENT MATRIX. FACTORS EXPLAINING THE 45\% OF THE VARIANCE OF THE PERCEPTION OF CHARISMA FROM BOSSI'S SPEECH THROUGH THE 67-ADJECTIVE SCALE OF CHARISMA.

\begin{tabular}{|c|c|c|c|}
\hline ADJECTIVES & FACTOR 1 & FACTOR 2 & FACTOR 3 \\
\hline Vigorous & .837 & & \\
\hline Active & .767 & & \\
\hline Dynamic & .766 & & \\
\hline Charming & .738 & & \\
\hline Attractive & .709 & & \\
\hline Courageous & .701 & & \\
\hline Convincing & .687 & & \\
\hline Captivating & .676 & & \\
\hline Seductive & .642 & & \\
\hline Bewitching & .604 & & \\
\hline Sexy & .592 & & \\
\hline Eloquent & .553 & & \\
\hline Determined & .540 & & \\
\hline Who Propose & .540 & & \\
\hline Visionary & .472 & & \\
\hline Wise & & .825 & \\
\hline Sage & & .825 & \\
\hline Prudent & & .737 & \\
\hline Calm & & .731 & \\
\hline Trustworthy & & 689 & \\
\hline Fair & & .645 & \\
\hline Intelligent & & .605 & \\
\hline Easygoing & & .585 & \\
\hline Honest & & .576 & \\
\hline Sagacious & & .527 & \\
\hline Sincere & & .514 & \\
\hline Determined & & & .508 \\
\hline Menacing & & & .775 \\
\hline Who Scares & & & .767 \\
\hline Dishonest & & & .762 \\
\hline Cold & & & .679 \\
\hline Individualistic & & & .642 \\
\hline Authoritarian & & & .585 \\
\hline Leader & & & .578 \\
\hline Untrustworthy & & & .563 \\
\hline Influent & & & .552 \\
\hline Confident & & & .523 \\
\hline Organised & & & .509 \\
\hline Resolute & & & .506 \\
\hline Egocentric & & & .485 \\
\hline Variance & $22.52 \%$ & $12.60 \%$ & $10.83 \%$ \\
\hline
\end{tabular}

among the three factors of charisma perception as tested by the means (Factor 3: 4.328; Factor 1: 3.531; Factor 2: 3.478).

An Anova analysis shows the significant main effect of the variable period (PRE vs. POST) on the perception of the Proactive-Attracting $(\mathrm{F}(1,126)=42.71 ; \mathrm{p}<0.000)$ and of the Authoritarian-Threatening charisma $(\mathrm{F}(1,126)=33.47$; $\mathrm{p}<0.000)$ ). This accounts for how in the PRE stroke period the vocal stimulus is perceived as more dominant (PRE 4.12 vs. POST 2.93) and more authoritarian (PRE 4.85 vs. POST 3.79). The opposite trend holds for the perception of the Benevolent-Competent charisma, since in the POST stimuli participants attribute the speaker a Benevolent-Competent charisma more than in the PRE, though not significantly $(\mathrm{p}=0.08)$.

The variable speech act affects Factor $1(\mathrm{~F}(1,126)=3.575$; $\mathrm{p}<0.025)$ and Factor $3(\mathrm{~F}(1,126)=8.560 ; \mathrm{p}<0.000)$ and the main effect confirms that the incitation, more than the assertion and the rhetorical question, causes the speaker to be perceived 


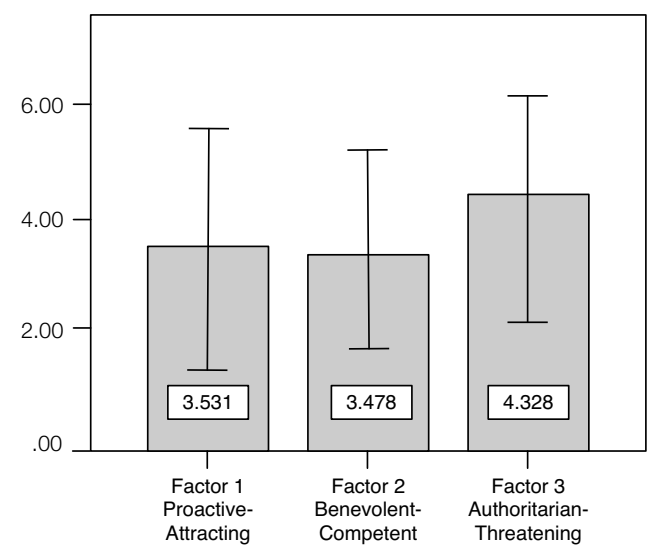

Fig. 3. Index of perception of the three factors of charisma with means value and Standard Deviation ( $\mathrm{X}$ axis) and means of ratings ( $\mathrm{Y}$ axis).

as having more of an attractive and an authoritarian charisma (Factor 1: 3.84 vs. 3.24 and 3.49; Factor 3: 4.70 vs. 4.47 and $3.80)$.

\section{Discussion}

This work presents a first step in the elaboration of a multidimensional theory of charisma and of its perception through the speech. As said above in section I the perception of charisma is of course based in the multimodal behavior of the leader (speech, gestures, postures, etc.) but here we only focused in the acoustic-prosodic parameters of the verbal part. After eliciting lists of adjectives that describe the positive and negative qualities of a charismatic person, we wondered how do these qualities leak from a political leader's speech, including both his acoustic-prosodic features and the type of speech acts he performs. To exploit a natural experiment in which the overall quality of speech has dramatically changed, thus possibly determining a variation in the perception of charisma, we submitted participants in a perception experiment to samples of voice of Umberto Bossi before and after a stroke, asking to rate them in terms of adjectives mentioning charismatic qualities.

While in a previous work [8] we analyzed the changes in Bossi's speech with respect to each single adjective, in this paper we clustered the charismatic qualities around three factors. The first, a Proactive-Attracting charisma, groups adjectives mentioning qualities of the dynamic leader (as vigorous, active, dynamic, courageous) that induce positive emotions in a receiver (for whom the leader is charming, attractive, captivating, seductive). The second, a Benevolent-Competent charisma, includes adjectives like intelligent, wise, calm, trustworthy, fair. The third, the Authoritarian-Threatening charisma, referred to adjectives like determined, menacing, dishonest, individualistic, authoritarian, evokes the "dark face" of charisma: a very determined but self-oriented leader whose dominance turns into authoritarianism.

Looking at the relation of these three factors with Bossi's speech, the first relevant result is that, overall, his voice is mainly perceived as bearing the Authoritarian-Threatening of charisma (Factor 3). Second, as to the variation of his speech from before to after the stroke, a dramatic collapse is evident in the Proactive-Attracting and in the Authoritarian-Threatening charisma, while the Benevolent-Competent charisma increases. Third, taking into account the differences among speech acts (see Fig. 4), incitation and assertion are in general highly correlated, both raising from PRE to POST for the Factor 2 Benevolent-Competent (Fig. 4b), and falling for Factor 1 (Fig. 4a) and Factor 3 (Fig. 4c), attractive and authoritarian, while the rhetorical question shows an opposite tendency as to Factor 2 (Fig. 4b). This means that Bossi's speech after the stroke takes up a different type of charisma, looking more as a wise/calm leader as opposed to the dynamic, fighting and threatening leader he looked at the beginning of his political career and that his speech is responsible for this impression.

\section{CONCLUSION AND PERSPECTIVES}

The work presented here contributes to the investigation on the notion of charisma in two senses. On the one side, it presents a specific study on how the perception of charisma in speech may vary due to the change in the acoustic-prosodic characteristics of speech, and thus contributes to single out which of them may be responsible for the perception of charisma. Yet, besides this, the theory of charisma presented here allows to distinguish different factors of charisma and to put each of them in correspondence with specific aspects of speech. Moreover, the data analysis proposed might allow to compare the speech of different leaders, and to assess their respective kinds of charisma. For example, the speech of one leader might receive high ratings on a factor and another one on a different factor (say, former French president Nicolas Sarkozy might score higher on Authoritarian charisma instead of present French president François Hollande higher that might score higher in Competent charisma).

An aspect of these results that is not yet clear is whether they are due more to change in Bossi's intonation contour or change in voice quality. This has also been investigated in [8] where we kept these features distinct by submitting subjects only to the synthesis of intonation contour.

Finally, to the extent to which both contributions of this work may be extended and deepened, while finding more systematic correspondences between types of charisma and acoustic features, the work done will eventually bear on the automatic analysis and synthesis of charismatic speech.

\section{ACKNOWLEDGMENT}

We would like to thank Paolo Mairano (GIPSA-Lab, CNRS, Grenoble, France) for his useful advice with the prosodic description of stimuli and Christophe Savariaux (GIPSA-Lab, CNRS, Grenoble, France) for his technical support in acoustic analysis. We also would like to thank the three anonymous reviewers for their feedback and helpful suggestions on the manuscript.

This research was partly supported by: a Doctoral Fellowship from the French Ministry of National Education and Research 
(years 2010-2013), by the 7th Framework Program, European Network of Excellence SSPNet (Social Signal Processing Network), Grant Agreement Number 231287 and by the "AIRES Culturelles" grant from the Stendhal University, Grenoble, France.

\section{REFERENCES}

[1] L. Cavalli, Carisma: la qualità straordinaria del leader. Rome, Italy: Laterza, 1995.

[2] P. Boss, "Essential attributes of charisma," Southern Speech Communication Journal, vol. 41, no. 3, pp. 300-313, 1976.

[3] M. Atkinson, Our Masters' Voices: Language and Body Language of Politics. London, UK: Routledge, 1984.

[4] A. Rosenberg and J. Hirschberg, "Charisma perception from text and speech," Speech Communication, vol. 51, no. 7, pp. 640 - 655, 2009. Research Challenges in Speech Technology: A Special Issue in Honour of Rolf Carlson and Björn Granström.

[5] P. Touati, "Prosodic aspects of political rhetoric," in ESCA Workshop on Prosody, (Lund, Sweden), pp. 168-171, September 27-29 1993.

[6] E. Strangert and J. Gustafson, "What makes a good speaker? subject ratings, acoustic measurements and perceptual evaluations," in Interspeech 2008, pp. 1688-1691, 2008

[7] P. Martin, "Autres styles: quelques variantes idiosyncratiques," in Intonation du Français, pp. 228-232, Armand Colin, 2009.

[8] R. Signorello, I. Poggi, D. Demolin, and F. D'Errico, "Charisma perception in political speech: difference between normal and disordered voice," in GSCP 2012, (Belo Horizonte, Brazil), February 29th - March 2nd 2012. Unpublished.

[9] B. J. Fogg, "Persuasive computers: perspectives and research directions," in Proceedings of CHI 1998, pp. 225-232, ACM Press, 1998.

[10] I. Poggi, "The goals of persuasion," Pragmatics \& Cognition, vol. 13, no. 2, pp. 297-336, 2005.

[11] Aristotle. Rhetoric. Translated by W. Rhys Roberts. Online: "The Internet Classics Archive" http://classics.mit.edu//Aristotle/rhetoric.html, accessed 22 Dec 2011

[12] I. Poggi, F. D'Errico, and L. Vincze, "Discrediting moves in political debate," in Proceedings of UMMS 2011 (P. Ricci-Bitti, ed.), pp. 84-99, Springer LNCS, 2011.

[13] D. P. Goleman, Emotional Intelligence: Why It Can Matter More Than IQ for Character, Health and Lifelong Achievement. New York, USA: Bantam Books, 1995.

[14] V. Firenzuoli, Le forme intonative di valore allocutivo dell' italiano parlato. Analisi sperimentale di un corpus di parlato spontaneo (LABLITA). $\mathrm{PhD}$ thesis, Università degli Studi di Firenze, 2001.

[15] J. Kreiman and D. Sidtis, Foundations of Voice Studies: An Interdisciplinary Approach to Voice Production and Perception. Oxford, UK: Wiley-Blackwell, 2011.

[16] T. Murry, "Speaking fundamental frequency characteristics associated with voice pathologies," Journal of Speech and Hearing Disorders, vol. 43, August 1978 .

[17] P. Martin, Intonation du Français. Paris, France: Armand Colin, 2009.

[18] P. Martin, "WinPitch W7 by Pitch Instruments Inc." Computer program, September 21 2011. http://www.winpitch.com/.

[19] G. Mohammadi, M. Mortillaro, and A. Vinciarelli, "The voice of personality: Mapping nonverbal vocal behavior into trait attributions," in International Workshop on Social Signal Processing, pp. 17-20, 2010. (a) Factor 1 - Proactive-Attracting charisma

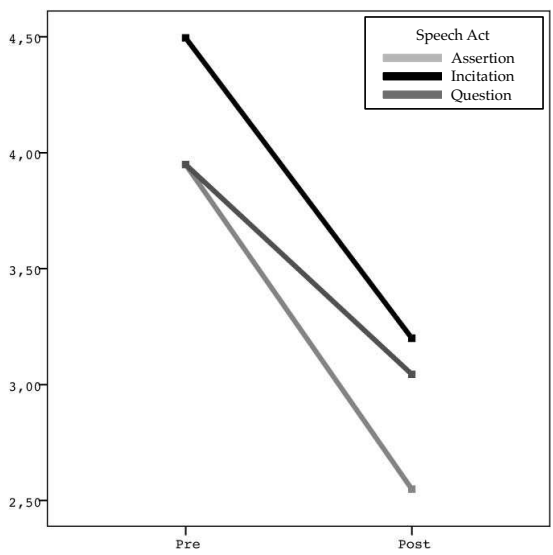

(b) Factor 2 - Benevolent-Competent charisma

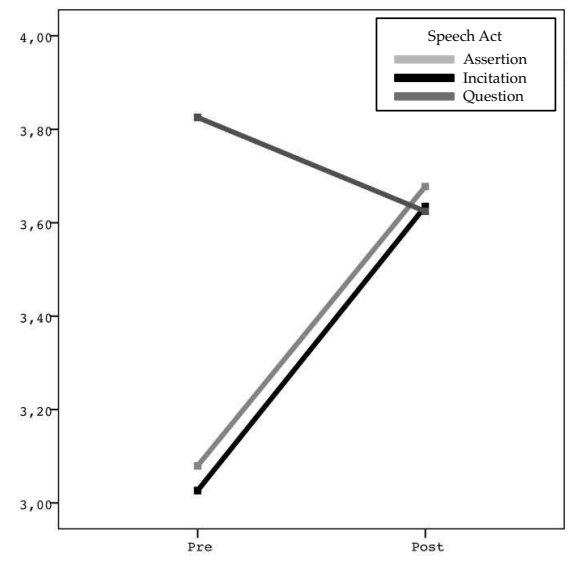

(c) Factor 3 - Authoritarian-Threatening charisma

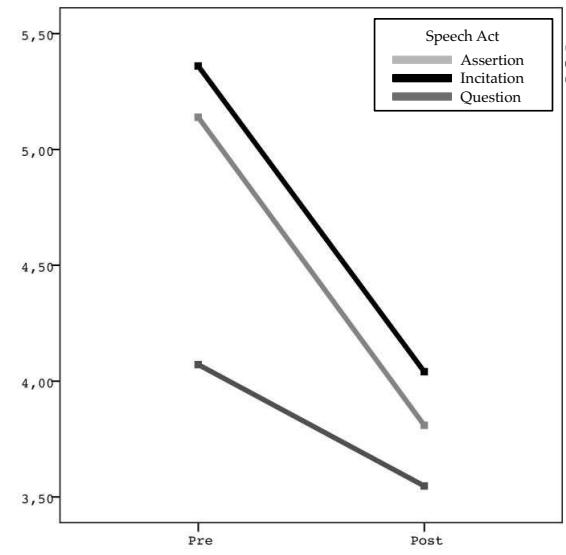

Fig. 4. Marginal means expected of ratings by factors, conditions and speech acts. X axis: condition PRE and POST stroke. Y axis: expected marginal means of ratings. 